\title{
Book Review: Higher Education and National Development: Universities and Societies in Transition
}

\author{
Edited by David Bridges, Palmira Juceviciene, Roberta Jucevicius, \\ Terence H. McLaughlin, and Jolanta Stankeviciute \\ New York, NY: Routledge, 2012. 336 pp. \\ ISBN: 978-0-41551400-2
}

In the wake of international adherence to economic liberalism, universities worldwide face challenges regarding responsiveness to the global market. As societies transform, so must the higher education institutions serving them. In the midst of this transition lays the conflict between the global, regional, and local, as well as the need to uphold national identity while simultaneously responding to the demands of globalization. Higher education is being re-purposed to meet the evolving requirements of countries in transition (CIT). Few regions have felt this transition stronger than the Central and East European countries (CEECs), where the restructuring in the aftermath of the collapse of the Soviet empire adds to their challenges.

Higher Education and National Development is a comprehensive work that examines the dual challenge faced by CEECs as they move away from the Soviet Union's systems in preparing to fill a greater role on the global arena. A particular emphasis is placed on higher education and the shifting role of universities in economic growth and development, along with the importance of performing a transformative role in society. In five sections, we are taken through the various changes currently in process in the emerging European countries of the post-Soviet nations.

The published results of this book derive from a multi-disciplinary project between Kaunas University of Technology in Lithuania and Von Hugel Institute, a multi-disciplinary research institute at St. Edmund's in Cambridge, Massachusetts). Seeking countenance from new authors, chapters do not represent a single point of view; rather, they pro- vide an impetus for readers to arrive at their own assumptions. A theme of the changing roles of higher education, an osmotic problem, is presented: "the university is ruined because it has lost its historical raison d'etre. It no longer has a role in safeguarding and propagating national cultures" (36).

From the author's definition of the postmodern university, its success depends on the higher education sector's increasing ability to function as a business, though whether this approach is viable in the preservation of traditional university roles is uncertain.

The authors in Part 1, "Universities, Societies and Transitions," set the backdrop of challenges faced by all universities transitioning into the "knowledge age," pinpointing CEECs. Robert Cohen introduces us to the numerous "fads" and phases of educational reforms, ranging from neoliberalism to the massification of higher education. He warns of monooptical views and deductive rationalities in higher education policy design, and opens up for discussion how international educational transfer might best be achieved. Richard Smith, however, calls for a more pragmatic approach to strengthening the link between the university and society, describing what he sees as five dimensions to university responsiveness.

Palmira Jucevičienè and Rimantas Vaitkus initiate Part 2 by citing the importance of developing higher education in the knowledge economy and knowledge society, whereby economic success depends on creation, dissemination and use of knowledge and information. CIT must adopt new attitudes toward the knowledge society in which they are embedded, 
with special focus on establishing relationships with local communities; irrefutably, identities and resources are being challenged by globalization. "In general, [CIT] must realize their potential to be treated as partners rather than 'third world' countries by their global counterparts, and take their place in the international and global stage" (43).

A correlation is made between knowledge created by academics and that which comes from practice to form the emerging idea of supercomplexity. Hence, with the development of the "multiversity" paradigm, we are seeing a shift in the university role. As the pressure from globalization continues to grow, however, can we expect higher education institutions to safeguard national culture and express a unique identity to the global community of universities?

Necessitating a new university identity, Robertas Jucevičius continues in the following chapter by identifying one such role essential to the development of learning societies, especially at the micro level with several models of learning societies cited. A key purpose of education is recounted, namely "to provide mature autonomous life, help engage in lifelong learning of abilities, and develop community spirit." Jucevičius broadens our view of community with the intelligent country, whereby the overcrowding of facts known as knowledge is of little use. Success in today's milieu no longer lies with specialized skills but with "intelligence": the agility in the use of resources with the capacity to use them faster and smarter than competitors. Will this pressure of global competitiveness, though, become a threatening sign for the degeneration of higher education?

In Part 3, the concepts of competitive development are challenged, and its relation to the market, population demographics, and education are explored. Flavio Comim provides a historic perspective, and demonstrates how an understanding of these models is crucial in assessing the relative position of the university in society. Furthering the debate is the potential for and responsibilities of higher education institutions in relation to economic growth, national development, and the flourishing of societies. In his chapter on regional economic development, Bridges refers to improving the region's competitiveness in the global economy. From his standpoint that universities represent "hubs of economic activity," Bridges outlays several measures to be taken in order to realize the economic benefits of university activities in regional infrastructures. The issues of regionalism and university outreach are further examined in Kazimierz Musial's chapter on regional universities in the Baltic Sea region identifying possible models for higher education interactions and contributions to regional economy, community, and culture. What are the implications of the regional university's capitalist "hub"? How will its traditional role as empirical researcher transform?

Part 4 moves away from the potential of universities in community development, and turns to the demands of the economy on higher education institutions, continuing the debate on research. Slavo Radoševic and Monika Kriaucioniene consider the role of education in national innovation systems in CEECs in general identifying several challenges and problems involved in the transformation of national systems of innovation. They find that there exists a gap between nominal capacities and actual investment in research and development, and that a disproportional focus on the "teaching-part" of universities is inhibiting their contributions to knowledge-based growth. Arunas Lukoševicius continues Radoševic and Kriaucioniene's discussion, and questions the current issues in technology transfer and higher education. Is it viable to define the university as a "sanctuary of science" or a "market-oriented enterprise"? To what extent does the capitalization of higher education research serve commercial purposes?

Providing a more cultural perspective, Giedrius Jucevičius uses Lithuania-based research as a footing for higher education strategy recommendations. The concept of "holistic competence development" is discussed in Daiva Lepaite's chapter, along with a discussion on which competencies are most critical in a knowledge-driven economy. In the last chapter of this section, Arild Tjeldvoll and Aukse Blazenaite call for equilibrium between academic freedom, institutional autonomy, and accountability toward business, describing their idea of a "critical service university." While accepting the emergence of an entrepreneurial culture in the university, as 
described by the other contributors in the book, Arild Tjeldvoll and Aukse Blazenaite question how this development will affect the core academic values of higher education. Will the dominance of market-oriented higher education policies erode the traditional principles of teaching, research, and academic autonomy?

Higher education's role as an agent of innovation is discussed in Part 5, and is presented as a complex one. Brigita Janiuynaite and Dalija Gudaitye cite the success of innovation implementation as being influenced by psychological and cultural factors at the level of the individual. Post-Soviet social changes are happening slowly, and tensions between a strong need for innovation on one hand and a tendency for conservatism on the other are emerging. Is it possible for higher education to lead a double role aiding emancipation of society through intellectual culture? Are CIT prepared for such a conversion so soon?

Irena Leliugierne and Viktorija Barsauskiene respond to these challenges with a call for universities to become actors in community development. This new economy calls for a new paradigm, one that embraces a learning individual as well as a learning community and a learning society. "Learn to learn" is the new slogan for a global economy (227). How will modern universities meet the challenge of a multiplicity of roles: that of educator, researcher and initiator?

Vilius Grabauskas further explores the schema of a community in the relationship of education as a socio-economic variable being a major contributor to existing inequalities in health status and mortality. Education needs to be recognized as a major influence in ameliorating social inequalities, including a reduction in mortality, an increase in life expectancy, and achievable equality in health and health care.

Rounding out citizenship, Hanan Alexander poses the question of just how deeply, if at all, higher education handles the interest in spiritual education, as well as the role that is played within democratic societies in transition. He contends that in order to create democratic citizens, universities need to promote education balancing the "common or universal with the distinctive or particular"
(251). Nevertheless, higher education institutions must decide if they are to teach, to convince or to inspire; balance is vital. How will higher education evolve within the ethical attitudes and framework of the liberal arts to foster development of a new curriculum?

Scientific research, teaching and development, including spiritual education, are among the major contributions of higher education to communities, and will affect the future of Europe and beyond, according to Sir Brian Heap in the final chapter of Part 5. Science, engineering and technology are changing the profile of universities" "useful science" and is underwriting wealth creation along with quality of life. How might this new entrepreneurial climate alter academic attitudes toward multidisciplinary projects between universities and private industry? While "centres of excellence" are engines of social recompense in CIT, the ancient virtue of wisdom cannot be divorced from this process. If so, will opportunism and exploitation, rather than discovery and knowledge for the greater good, become salient?

Part 6 serves as a united platform for continued examination of issues, challenges, and ideas presented throughout the book. Barbara Zamorski debates the quality of higher education under the transitional phase in which CEECs presently find themselves. In addition to evaluating scenarios for the future of higher education, she proposes alternative indicators of quality that include pluralism of teaching, educators' sense of responsibility, intrinsic passion for subjects and disciplines, and inclusive higher education. Zamorski contends that one of the paramount challenges in public service today is how to marry sound managerial policies addressing audits without deflation of traditional missions of universities. The final chapter, written by Terence McLaughlin, requests a fuller assessment of concepts like "learning society," particularly in the "countries in transition." The author recognizes a need for the university to preserve its traditional values of emancipation and fostering independent critical thinking. As the forces of the economy continue to shape higher education, McLaughlin argues that it is imperative to formulate strategies aimed at preserving the humanizing role of the university. 
National culture and identity, vehemently defended under Soviet rule, is now eroding under global forces, along with ethical valuations. An intricate web of tensions, on both theoretical and practical levels, exists for CIT, and McLaughlin asserts that qualities of judgment and wisdom reign in welcoming these transitions to society and universities.

Clearly, higher education is forced to re-purpose and re-think its role to meet the evolving needs of CIT. Universities are required to be "everything to everyone" from the micro level of the individual to the macro level of governments and global partners. The challenge remains as to how these humanizing roles might be preserved and protected, and while this book serves as a sound foundation for further discussion, it leaves several scenarios unspecified. Which way the pendulum will swing is left up to the reader as intelligence is employed in deducing the outcome.

Reviewed by Ada Mary Tremonte and Inga Storen Drexel University, USA 